\title{
PNAIC: CONTRIBUIÇÕES PARA AS PRÁTICAS DE ALFABETIZAÇÃO NA VISÃO DE GESTORES EDUCACIONAIS
}

\author{
Andréa Ramos de Oliveira, Ana Luzia Videira Parisotto \\ Universidade Estadual Paulista - UNESP, Programa de Pós-Graduação em Educação, Presidente Prudente, SP. E-mail: \\ andrearamosos@hotmail.com.
}

\begin{abstract}
RESUMO
Como alternativa para alfabetizar todas as crianças até os 8 anos de idade, quinta meta do PNE, foi implantado o PNAIC. Por sua relevância, objetivou-se pesquisar mudanças que o PNAIC-Língua Portuguesa promoveu na prática pedagógica de professores de 30 ano do ensino fundamental de duas escolas de Birigui, sendo sujeitos da pesquisa docentes e gestores. A metodologia utilizada teve abordagem qualitativa, com opção pelo estudo de caso e utilização de questionários. 0 presente artigo é recorte de pesquisa de mestrado e pretende apresentar a visão dos gestores sobre o PNAIC. Os resultados revelaram uma lacuna entre discussões fomentadas pelo Pacto e a formação na unidade, havendo descompasso entre programas de formação do MEC, da Secretaria de Educação e da escola, parecendo propostas distintas, quando guiadas pelos mesmos princípios, ainda que, no caso do município pesquisado, tenha havido envolvimento de gestores.

Palavras-chave: PNAIC, formação de professores, gestores, alfabetização, ensino de língua materna.
\end{abstract}

\section{PNAIC: CONTRIBUTIONS FOR LITERACY PRACTICES IN EDUCATIONAL MANAGERS VISION}

\begin{abstract}
As an alternative to alphabetize all children up to 8 years old, the fifth goal of the PNE, was deployed PNAIC. For its relevance, it was aimed to investigate the changes that PNAIC-Portuguese Language promoted in the teachers' pedagogical practice from the $3^{\text {rd }}$ grade of Elementary School in two schools in Birigui, being as subjects of the research teachers and managers. The methodology used had a qualitative approach, with option for the study of the case and the use of questionnaires. The present article is the profile of a master's degree research and it intends to present the managers' view about PNAIC. The results revealed a gap between discussions fostered by the Pact and the formation at the unit, existing mismatch between the MEC training programs, the Department of Education and the school, seeming different proposals, when guided by the same principles, even if in the case of the researched county, there has been involvement of managers.
\end{abstract}

Keywords: PNAIC, teacher training, managers, literacy, native language teaching. 


\section{INTRODUÇÃO}

O PNE, Lei no 13.005, de 25/06/2014, apresenta diretrizes, destacando: erradicação do analfabetismo, melhoria da qualidade da educação e valorização dos profissionais da educação, definindo como 5a meta alfabetizar todas as crianças, no máximo, até o final do 30 ano do ensino fundamental (BRASIL, 2014). Orientadoras de ações de formação continuada em âmbito nacional, seu entendimento exige ultrapassar a concepção como complementação da formação inicial, tampouco que seja considerada "apenas como atualização científica, pedagógica e cultural do professor" (IMBERNÓN, 2010, p.72). O desafio é estabelecer o equilíbrio entre teoria e prática, promovendo interação entre esses dois componentes, numa visão dialética da formação. A esse respeito, Imbernón (2009, p. 9) assegura que "Para a formação permanente do professorado será fundamental que o método faça parte do conteúdo, ou seja, será tão importante o que se pretende ensinar quanto a forma de ensinar". A mudança do contexto educacional pede, assim, uma redefinição do conceito de formação continuada.

Para Rudduck (1991 apud VAILLANT e MARCELO, 2012, p.167), o desenvolvimento profissional se refere à "capacidade de um docente para manter a curiosidade sobre a sala de aula; identificar interesses significativos no processo de ensino e aprendizagem; valorizar e buscar o diálogo com colegas experientes, como apoio na análise de dados", não ocorrendo sem a reflexão sobre a prática, nem desvinculado de demandas cotidianas da atuação. Segundo Marcelo García (1999, p. 193), trata-se de "um processo de aprendizagem mediante o qual alguém (professores, diretores) deve aprender algo (conhecimentos, competências, disposições, atitudes), num contexto concreto (escola, universidade, centro de formação), implica um projeto, desenvolvimento e avaliação curricular" [grifos do autor]. Candau (2011, p. 64) alerta não se poder conceber "como um meio de acumulação (de cursos, seminários, etc., de conhecimentos ou de técnicas), mas sim através de um trabalho de reflexividade crítica sobre as práticas e de (re)construção permanente de uma identidade pessoal e profissional, em interação mútua", apontando três aspectos como fundamentais: consideração da escola como lócus privilegiado de formação; valorização do saber docente; ciclo de vida dos professores.

Estudos sobre formação docente inflamaram discursos sobre a necessidade de inovações nos processos, no entanto inovação não é objetivo facilmente alcançado, impondo que políticas sejam delineadas. O contexto é complexo, o objetivo nobre, a tarefa árdua, os atores múltiplos. Para Gatti (2008, p. 37), no Brasil, nas últimas décadas, "a educação continuada foi colocada como aprofundamento e avanço nas formações profissionais [...] o que exigiu o desenvolvimento de políticas nacionais ou regionais em resposta a problemas característicos de nosso sistema educacional", acrescentando que "Muitas das iniciativas públicas de formação continuada no setor educacional adquiriram, então, a feição de programas compensatórios e não propriamente de atualização e aprofundamento em avanços do conhecimento". Políticas públicas de formação terão validade ao se aproximarem da constatação do complexo e da multiplicidade de contextos e de saberes docentes, mostrando-se despidas do caráter aligeirado e milagroso. O compromisso político e social imposto pela 5 a meta do PNE exige ações que não esgotem possibilidades nem reduzam atores. O PNAIC mostra-se uma das alternativas, mas não se configura a única. Conhecer o contexto de sua instituição permite entender o desafio da alfabetização como direito.

A Portaria MEC no 867, de 04/07/2012, apresenta o PNAIC - Pacto Nacional pela Alfabetização na Idade Certa como acordo formal assumido pelo Governo Federal, estados e municípios e entidades para firmar o compromisso de alfabetizar crianças até, no máximo, 8 anos de idade, ao final do ciclo de alfabetização. Com pretensão ousada e alto investimento financeiro perto de $\mathrm{R} \$ 1,5$ bilhão para 2013 -, reforçou o discurso da alfabetização como prioridade nacional, no entanto não se distancia do que historicamente tem sido o entendimento acerca da necessidade de oferecer formação continuada aos profissionais da educação. Adotou um modelo "em cascata", "no qual um primeiro grupo de profissionais é capacitado e transforma-se em 
capacitador de um novo grupo que por sua vez capacita um grupo seguinte", que, embora envolva número expressivo de profissionais, não tem efetividade significativa verificada quanto à difusão de fundamentos para uma mudança profunda (GATTI e BARRETO, 2009, p. 202).

Assim, o objetivo deste artigo é refletir sobre contribuições e fragilidades do PNAIC-Língua Portuguesa, desenvolvido em 2013, na visão de gestores escolares. As considerações ora apresentadas, recortes de estudo mais amplo, integram pesquisa de mestrado que investiga as contribuições do programa para a formação do aluno leitor e produtor de textos na prática de professores de 3으 ano do Ensino Fundamental de duas escolas do município de Birigui, interior do estado de São Paulo - doravante identificadas escola A e escola B.

\section{METODOLOGIA}

Esta seção apresenta a metodologia em que se enquadra a pesquisa empírica - estudo de caso de natureza qualitativa e interpretativa -, submetida ao Comitê de Ética em Pesquisa e aprovada para desenvolvimento - CAAE: 53028916.6.0000.5402, comprovante $\mathrm{n}$ 0 007404/2016. A opção por investigação de abordagem qualitativa justifica-se pela intencionalidade explicitada de compreender a realidade posta pelo advento do PNAIC aos professores das escolas selecionadas. Abordagens qualitativas, para André (2013, p. 97), "se fundamentam numa perspectiva que concebe o conhecimento como um processo socialmente construído pelos sujeitos nas suas interações cotidianas, enquanto atuam na realidade, transformando-a e sendo por ela transformados". Para a reflexão crítica acerca da formação continuada oferecida aos professores da rede de ensino selecionada, neste recorte segundo a visão dos gestores, o estudo de caso se faz pertinente por permitir considerar o quanto os sujeitos pesquisados incorporaram em seu trabalho cotidiano as concepções abordadas durante o PNAIC.

Para a coleta de dados (gestores e professores), o instrumento selecionado foi o questionário - "instrumento de coleta de dados constituído por uma série de perguntas, que devem ser respondidas por escrito" (MARCONI \& LAKATOS, 1999, p.100) -, e mostrou-se importante para investigar os processos de formação continuada analisados sob a perspectiva dos envolvidos. Com relação aos professores, foram analisados planejamentos de propostas e feita observação da aula, estabelecendo-se o diálogo entre informações coletadas nos questionários e o observado na prática, permitindo comparações do discurso assumido e da prática verificada.

\section{RESULTADOS}

O município selecionado, com população estimada de 118.352 habitantes, sendo 97.095 alfabetizados (IBGE, 2016), possui 16 escolas de ensino fundamental. Matrículas no Ensino Fundamental, em 2016, somam 11.620, sendo 5.984 no Ensino Fundamental regular de 1응 a응 ano, das quais 3.593 em turmas de alfabetização - 1ㅇ, 2ㅇ e 3ㅇ ano (SEMEBI, 2016). Em atendimento ao disposto na LDB no 9.394, de 20/12/1996, Título IV, Art. 8o, possui sistema de ensino próprio organizado, em regime de colaboração com a União e com o Estado (BRASIL, 1996). A educação municipal evidencia crescimento e, em 2013, o IDEB observado - 7,3 - ultrapassou a meta projetada para 2021, consequência de uma evolução de rede, não de escolas isoladas.

O Art. 6ㅇ da LC no 32, de 17/09/2010, que dispõe sobre o Estatuto e Plano de Carreira do Magistério Público e dos Profissionais de Apoio Educacional do município, determina provimento efetivo de cargos, por concurso de provas e títulos, prevendo, ainda, cargos em comissão e função gratificada. O Art. 7ํ divide os profissionais em classes: de Docentes, de Especialistas em Educação e de Apoio Educacional. Da classe de Especialistas, coordenadores pedagógicos e vice-diretores são efetivos do magistério ocupantes de função gratificada. A escola pode optar por dois coordenadores ou um coordenador e um vice-diretor; há incentivo financeiro maior para a função de coordenador, que exige apresentação de proposta e eleição dos pares. 
A escola A iniciou atividades em 01/02/2012, criada pelo Decreto no 4.809 de 01/12/2011. Funciona em salas cedidas ou adaptadas (divisórias) no Instituto Federal de Educação, Ciência e Tecnologia, campus de Birigui; possui cerca de 300 alunos dada a limitação do espaço físico concedido. Desde seu início, passaram pela gestão três diretoras, nomeadas por concurso público. Em 2015 ingressou na rede e na unidade uma diretora que não manifesta interesse em se remover. Em 2014 e 2015, não havia coordenador pedagógico. Em 2016, uma docente da unidade passou a ocupar a função. É válido destacar que o corpo docente permanece o mesmo, embora fragilizado pela falta de direcionamento que as trocas na gestão representaram. A escola B teve Ato de Criação pelo Decreto 33.072 de 14/03/91 - Resolução SE 72 de 24/04/91. Incorporada à rede municipal através de Decreto 3.136 de 10/04/2000, retroativo a 1o de agosto de 1999, em virtude de assinatura de convênio celebrado entre SEE-SP e Prefeitura Municipal de Birigui, em 26/07/1999, atende perto de 780 alunos. A diretora mantém-se na unidade desde o seu ingresso na rede, em 2008. Possui duas coordenadoras, uma desde 2006 e a outra desde 2008; tem-se a mesma equipe há 9 anos. A equipe pedagógica não tem alterações frequentes.

Responderam aos questionários dos gestores três coordenadores e um diretor. Todos declararam participar de formações da Secretaria Municipal e 75\% cursaram o PNAIC/2013, um como professor alfabetizador. O Quadro 1 resume o perfil dos respondentes:

Quadro 01. Sexo, idade, tempo no magistério, tempo na gestão e formação dos respondentes

\begin{tabular}{|c|c|c|c|c|}
\hline Sexo & Idade & $\begin{array}{c}\text { Tempo no } \\
\text { magistério }\end{array}$ & Tempo na gestão* & Formação \\
\hline $100 \%$ & Mais de 50 anos: & Mais de 30 anos: & Menos de 2 anos: & Pedagogia: $100 \%$ \\
feminino & $75 \%$ & $50 \%$ & $50 \%$ Entre 5 e 10 & Segunda graduação: \\
& Entre 25 e 30 anos: & Entre 20 e 25 anos: & anos: $50 \%$ & $75 \%$ \\
& $25 \%$ & $25 \%$ & & Especialização: \\
& & Entre 5 e 10 anos: & & $100 \%$ \\
& & $25 \%$ & & Mestrado: $25 \%$ \\
\hline
\end{tabular}

* No caso das duas escolas, os gestores não exerceram a função em outra unidade.

Fonte: Dados organizados pelas pesquisadoras a partir dos questionários.

Sobre a influência do Pacto na formação, $50 \%$ responderam não ter modificado concepções de trabalho com Língua Portuguesa, 25\% afirmaram que houve modificações e $25 \%$ não participaram dessa edição. Respostas mais indicadas acerca de contribuição, potencialidade, fragilidade e entraves percebidos encontram-se no Quadro 2.

Quadro 02. Contribuição, potencialidade, fragilidade e entraves do PNAIC na visão dos respondentes

\begin{tabular}{|c|c|c|c|}
\hline Contribuição do curso & Potencialidade do PNAIC & Fragilidade do PNAIC & Entraves \\
\hline $\begin{array}{c}\text { Maior propriedade na } \\
\text { formação do corpo } \\
\text { docente. }\end{array}$ & $\begin{array}{c}\text { Utilização do material } \\
\text { teórico produzido pelo }\end{array}$ & $\begin{array}{c}\text { Elaboração de } \\
\text { instrumentos de } \\
\text { avaliação e discussão de } \\
\text { MEC. }\end{array}$ & $\begin{array}{c}\text { Resistência docente a } \\
\text { novas metodologias e } \\
\text { construção coletiva em } \\
\text { relação aos direitos de } \\
\text { aprendizagem. }\end{array}$ \\
\hline
\end{tabular}

Fonte: Dados organizados pelas pesquisadoras a partir dos questionários.

Sobre as contribuições para o trabalho docente, os gestores pesquisados declararam: 
Tabela 01. Contribuições do PNAIC para o trabalho docente na visão dos respondentes

\begin{tabular}{l|c|c|c} 
& Concordo & $\begin{array}{c}\text { Concordo } \\
\text { em parte }\end{array}$ & Discordo \\
\hline $\begin{array}{l}\text { Têm mais segurança para atuar com alfabetização e } \\
\text { letramento }\end{array}$ & & $100 \%$ & \\
\hline Esclareceram dúvidas sobre alfabetização e letramento & & $100 \%$ & \\
\hline Tornaram-se profissionais mais qualificados & $50 \%$ & $50 \%$ & \\
\hline Melhoraram o planejamento de sequências didáticas & $50 \%$ & $50 \%$ & \\
\hline $\begin{array}{l}\text { Ampliaram conhecimentos acerca de alfabetização e } \\
\text { letramento }\end{array}$ & $50 \%$ & $50 \%$ & \\
\hline $\begin{array}{l}\text { Ampliaram conhecimentos acerca de gêneros discursivos } \\
\text { Ampliaram conhecimentos acerca do trabalho com sequências } \\
\text { didáticas }\end{array}$ & $50 \%$ & $50 \%$ & \\
\hline $\begin{array}{l}\text { Apropriaram-se de outras metodologias de trabalho } \\
\text { Ampliaram a competência reflexiva sobre sua prática } \\
\text { pedagógica }\end{array}$ & $50 \%$ & $50 \%$ & $50 \%$ \\
\hline $\begin{array}{l}\text { Tornaram-se pessoas mais estudiosas e interessadas nos } \\
\text { estudos da área }\end{array}$ & & $50 \%$ & \\
\hline $\begin{array}{l}\text { Realizam seleção mais criteriosa de textos e materiais } \\
\text { pedagógicos }\end{array}$ & & $100 \%$ & \\
\hline $\begin{array}{l}\text { Desenvolveram a percepção para a riqueza do trabalho } \\
\text { colaborativo }\end{array}$ & $50 \%$ & $50 \%$ & \\
\hline
\end{tabular}

Fonte: Dados organizados pelas pesquisadoras a partir dos questionários.

Dados gerais sobre o curso em relação à unidade escolar indicam:

Quadro 03. Aproveitamento dos professores e avaliação geral do curso na visão dos respondentes

\begin{tabular}{|c|c|c|c|}
\hline \multicolumn{2}{|c|}{ Aproveitamento dos professores } & \multicolumn{2}{c|}{ Avaliação geral do curso } \\
\hline $50 \%$ Bom (escola A) & $\begin{array}{c}50 \% \text { Razoável } \\
\text { (escola B) }\end{array}$ & $50 \%$ Bom (escola A) & $\begin{array}{c}50 \% \text { Razoável } \\
\text { (escola B) }\end{array}$ \\
\hline
\end{tabular}

Fonte: Dados organizados pelas pesquisadoras a partir dos questionários.

Todos os sujeitos pesquisados declararam ter acompanhado e feito interferências nas tarefas que eram solicitadas aos docentes, desenvolvidas por professores de cada segmento conjuntamente, mas reconhecem ter havido pouca integração de estudos ao projeto de formação da escola. As leituras exigidas no curso foram utilizadas para a formação em HTPCs, no entanto uma unidade o fez somente com os cursistas do PNAIC e outra estendeu ao grupo-escola. Questionados sobre incorporação de inovações aprendidas durante o curso, todos responderam "concordar em parte". Sugerem o oferecimento a todos os professores, independente do ano de atuação. Os gestores cursaram outros programas de formação do MEC e/ou da SEE.

\section{DISCUSSÃO}

O PNAIC tem significação valiosa por sua abrangência. Trouxe formação estruturada em princípios, divulgando uma cultura formativa que, uma vez consolidada, não volta a ser o que já foi outrora. No entanto, há uma crítica que se fundamenta e que Souza (2006, p. 485) discorre como sendo a apropriação do "argumento da incompetência", que traz para o foco de atenção "mais os professores e menos as escolas e o sistema educacional" [grifos da autora]. Embora incorra na responsabilização um tanto quanto isolada do professor alfabetizador, principalmente ao se considerar que não houve intenção formalizada de acompanhamento de gestores escolares nas 
ações formativas do Pacto, entende-se que há ganhos em sua implantação essencialmente por se reconhecer o propósito de pensar "a melhoria da educação a partir da prática profissional dos professores", sabendo-se que "uma formação centrada nas escolas e nos saberes produzidos pelos professores ao longo de sua vida profissional pode exercer um importante papel para a transformação dos professores e das escolas" (CANDAU, 2011, p. 87).

O município pesquisado, na apropriação do Pacto e no exercício de sua relativa autonomia, ampliou a oferta do curso e inseriu nas turmas os gestores educacionais (diretores, coordenadores, supervisores) e os professores auxiliares. Esse diferencial reforçou a concepção da rede de que a formação continuada dos professores é uma responsabilidade compartilhada, validando o espaço escolar como lugar de aprendizagem e da constituição da identidade profissional. Nesse sentido, a não inclusão dos gestores escolares em âmbito nacional pode ter significado um isolamento maior dos professores alfabetizadores, refletindo ainda mais no distanciamento das vozes dos sistemas e da escola. Mesmo no caso analisado, ainda que os gestores estivessem cursando o PNAIC com os docentes, é possível constatar que houve uma lacuna entre as discussões fomentadas no curso e a formação de cada unidade, cabendo refletir que as ações do programa seriam mais intensificadas à medida que integradas e incorporadas à formação das escolas. Quando os sujeitos pesquisados qualificam o Pacto como "bom" ou "razoável", não se referem diretamente ao programa em si (material, organização, dinâmica dos encontros), mas à apropriação que é feita ao longo desse processo de "pensar a prática como objeto de estudo". Isso se evidencia nos questionários quando avaliam o suporte pedagógico oferecido por eles próprios, indicado como "suficiente em partes" ou "insuficiente", e pelos orientadores de estudo, em alguns casos apontados como "suficiente em partes" e "não houve esse apoio". Ao acrescentar que "o PNAIC não era o foco principal da formação na UE" revela-se o descompasso entre os programas de formação do MEC, da Secretaria de Educação e da escola, de forma a parecer que eram propostas distintas, quando, na verdade, guiadas pelos mesmos princípios formativos. Essa desarticulação ou essa sensação de "desorientação" dos gestores escolares poderia ter sido minimizada se a implantação do Pacto tivesse sido acompanhada de discussões entre gestores e de acompanhamento das ações formativas nas escolas articulada pelo coordenador local designado pela Secretaria Municipal para que o programa não fosse entendido como desvinculado de projeto maior de formação de rede.

\section{CONCLUSÃO}

A implantação do PNAIC se justifica pela necessidade de políticas mais assertivas para a resolução do problema do analfabetismo e do analfabetismo funcional no Brasil. Envolveu, em 2013, 5.420 municípios do total de 5.570 indicados pelo IBGE (CARDOSO, 2016), revelando o caráter ousado do programa pelo contingente expressivo de sujeitos envolvidos.

Através do desenvolvimento de estudo de caso em que houve utilização de questionários, apresentou-se, como recorte de pesquisa de mestrado, a visão dos gestores pesquisados sobre o Pacto, sendo possível entender que o "discurso do PNAIC" caminhou paralelamente ao "discurso da escola", havendo raros pontos de convergência e configurando um "curso oferecido pelo MEC" e viabilizado pela Secretaria de Educação, mas não assumido pela escola e, portanto, não constatada mudança significativa na prática docente segundo os gestores sujeitos da pesquisa.

\section{REFERÊNCIAS}

ANDRÉ, Marli E. Dalmazo Afonso de. O que é um estudo de caso qualitativo em Educação? Revista da FAEEBA - Educação e Contemporaneidade, Salvador, v. 22, n. 40, p. 95-103, jul./dez. 2013.

BIRIGUI. Lei Complementar no 32. Dispõe sobre o Estatuto e Plano de Carreira do Magistério Público e dos Profissionais de Apoio Educacional do Município de Birigui. Birigui, SP, 17 set. 2010. 
Disponível em: http://www.birigui.sp.gov.br/educacao/site/admin/arquivos/estatuto 2010.pdf. Acesso em 18 jul. 2016.

BRASIL. Lei $n$ 0 9.394. Estabelece as diretrizes e bases da educação nacional. Casa Civil, Brasília, DF, 20 dez. 1996. Disponível em: http://www.planalto.gov.br/ccivil 03/leis/L9394.htm. Acesso em 12 jul. 2016.

BRASIL. Portaria MEC no 867. Institui o Pacto Nacional pela Alfabetização na Idade Certa e as ações do Pacto e define suas diretrizes gerais. Ministério da Educação, Brasília, DF, 04 jul. 2012. Disponível em: http://pacto.mec.gov.br/images/pdf/port 867 040712.pdf. Acesso em 16 mai. 2016.

CANDAU, Vera Maria. Magistério: construção cotidiana. 7. ed. Petrópolis, RJ: Vozes, 2011.

CARDOSO, Mônica. Pnaic chega à reta final acenando resultados e desafios. Disponível em: http://www.plataformadoletramento.org.br/em-revista/972/pnaic-chega-a-reta-final-acenandoresultados-e-desafios.html. Acesso em 28 jul. 2016.

GATTI, Bernadete Angelina. Análise das políticas públicas para formação continuada no Brasil, na última década. Revista Brasileira de Educação, v. 13, n. 37, jan./abr. 2008. p. 57-70. https://doi.org/10.1590/S1413-24782008000100006

GATTI, Bernadete Angelina; BARRETO, Elba Siqueira de Sá. Professores do Brasil: impasses e desafios. Brasília: UNESCO, 2009.

IBGE. Cidades. São Paulo. Birigui. Disponível em: http://cidades.ibge.gov.br/xtras/perfil.php?codmun=350650. Acesso em 18 jul. 2016.

IDEB. Resultados e metas. Disponível em: http://ideb.inep.gov.br. Acesso em 12 jul. 2016.

IMBERNÓN, Francisco. Formação permanente do professorado: novas tendências. São Paulo: Cortez, 2009.

IMBERNÓN, Francisco. Formação docente e profissional: formar-se para a mudança e a incerteza. 8. ed. São Paulo: Cortez, 2010.

MARCELO GARCIA, Carlos. Formação de professores. Para uma mudança educativa. Porto: Porto Editora, 1999.

SEMEBI. Matrículas - Ensino fundamental. Disponível em: semebi.net. Acesso em: 18 jul. 2016.

SOUZA, Denise Trento Rebello de. Formação Continuada e fracasso escolar: problematizando o argumento da incompetência. Educação e Pesquisa, São Paulo, v.32, n.3, p. 477-492, set./dez. 2006. Disponível em: http://www.scielo.br/pdf/ep/v32n3/a04v32n3.pdf. Acesso em 18 jul. 20016.

VAILLANT, Denise; MARCELO, Carlos. Ensinando a ensinar: as quatro etapas de uma aprendizagem. Curitiba: Ed. UTFPR, 2012. 